\title{
Percepção de agricultores familiares de Ubatuba - SP sobre serviços ecossistêmicos
}

\author{
Vívian Oliveira Kadry ${ }^{1 *}$ \\ Fatima C. Márquez Piña-Rodrigues ${ }^{2}$ \\ Augusto João Piratelli ${ }^{2}$ \\ ${ }^{1}$ Pós-Graduação em Agroecologia e Desenvolvimento Rural \\ Universidade Federal de São Carlos, Araras - SP, Brasil \\ Rua Alzira Domingues de Oliveira, 956, CEP 18609-270, Botucatu - SP, Brasil \\ ${ }^{2}$ Universidade Federal de São Carlos, Departamento de Ciências Ambientais (CCTS), Campus de Sorocaba \\ SP 264, Km 110, CEP 18052-780, Sorocaba - SP, Brasil \\ * Autor para correspondência \\ vivisok@gmail.com
}

Submetido em 18/05/2017

Aceito para publicação em 30/10/2017

\section{Resumo}

A percepção de serviços ecossistêmicos é uma ferramenta no estabelecimento de ações para conservação de ecossistemas, em especial em áreas cobertas pela Floresta Atlântica como Ubatuba - SP, onde habitam comunidades que utilizam serviços gerados pela natureza. Este estudo avaliou a percepção sobre serviços ecossistêmicos de 20 agricultores familiares que praticam agricultura de base ecológica em Ubatuba. Realizaramse entrevistas semiestruturadas para identificar os serviços percebidos pelos agricultores. As respostas foram classificadas de acordo com as funções de regulação, de habitat, de produção e de informação. A seguir realizou-se o cálculo do Índice de Consolidação da Percepção do Ecossistema (ICPE). De forma geral houve baixa percepção dos serviços ecossistêmicos, sendo regulação e informação as funções que obtiveram ICPE mais elevado. Houve dissociação da relação entre floresta e produção agrícola, pois os serviços gerados pela função de habitat foram percebidos por apenas $30 \%$ dos agricultores. Os resultados evidenciaram a necessidade de uma visão integrada de Assistência Técnica e Extensão Rural agregando os órgãos de extensão e de conservação, os quais devem considerar os agricultores protagonistas de qualquer processo a ser implementado. Assim, é possível proteger a cultura local e seu conhecimento tradicional ao mesmo tempo em que se conserva a Floresta Atlântica.

Palavras-chave: Agricultura de base ecológica; Agricultura familiar; Comunidades tradicionais; Floresta Atlântica

\section{Abstract}

Perception of ecosystem services by family farmers in Ubatuba - SP. The perception of ecosystem services can be used as a tool for the establishment of ecosystem conservation actions, especially in areas of Atlantic forest such as Ubatuba - SP, where communities use the services generated by nature. This study evaluated the perception of ecosystem services of 20 family farmers that practice ecologically-based farming in Ubatuba. Semi-structured interviews were used to identify which services were perceived by the farmers. The responses were classified according to the functions of regulation, habitat, production and information and 
used to calculate the Ecosystem Perception Consolidation Index (ICPE). In general, there was low perception of the ecosystem services, and regulation and information functions received higher ICPE scores. There was dissociation of the relationships between forest and agricultural production because the services generated by the habitat function were perceived only by $30 \%$ of the farmers. These results highlight the need to incorporate integrated technical assistance linking extension and conservation agencies, which should consider farmers as protagonists of any process for potential implementation. In this way, it is possible to protect the local culture and traditional knowledge while preserving the Atlantic forest.

Key words: Atlantic Forest; Ecology-based agriculture; Family farming; Indigenous people

\section{Introdução}

A história da agricultura nos mostra que há mais de 10 mil anos o ser humano vem transformando a natureza ao seu redor para extrair ou gerar os elementos essenciais para o seu bem-estar (SWINTON et al., 2007; MAZOYER; ROUDART, 2010). Até o advento da Revolução Verde ${ }^{1}$ na década de 1970, a forma como se praticava a agricultura promovia a biodiversidade e mantinha os recursos naturais dos quais dependia a prática agrícola (ASSIS, 2006; CAPORAL, 2009). Os agricultores apresentavam alto nível de percepção do ambiente ao seu redor; muito desse conhecimento ainda é perpetuado em algumas dessas comunidades (CAMPOS et al., 2011). Ao compreender e conhecer o ecossistema circundante, visualiza-se a necessidade de conservação dos recursos dele provenientes para a manutenção da reprodução familiar (VODOUCHÊ et al., 2010; TOLEDO; BARRERA-BASSOLS, 2009).

A relação entre o ser humano e a natureza leva ao conhecimento de diversos processos ecológicos (GLIESSMAN et al., 2007). Essa característica pode ser encontrada tanto em integrantes de comunidades rurais tradicionais (BARRERA-BASSOLS; TOLEDO, 2005), que sobrevivem do extrativismo, da pesca e da agricultura de subsistência, por meio de conhecimentos tradicionais sobre o ambiente natural (DIEGUES, 2001); como em agricultores não tradicionais (FLEURY; ALMEIDA, 2007). As comunidades não tradicionais podem ser compostas por agricultores familiares, que por estarem em contato com a natureza e dependerem desta para sobreviver adquirem percepções sobre os processos que ocorrem no ecossistema ao seu redor (FLEURY; ALMEIDA, 2007).

A Mata Atlântica é um dos biomas mais degradados do Brasil, e seu domínio atual é estimado entre 11,4\% e $16 \%$ do original (RIBEIRO et al., 2009). Considerada como hotspot ${ }^{2}$, vem sendo devastada, restando apenas fragmentos espalhados pelo país (GUEDES et al., 2005). No estado de São Paulo, a agricultura convencional, a urbanização e a industrialização foram os principais responsáveis pela destruição de parte representativa dessa formação florestal (DALMORA, 2004). Apesar desse panorama, o estado é o que possui os contínuos mais conservados do país (SILVA, 2008). A maioria desses remanescentes está protegida por unidades de conservação (UC), as quais estão em contato direto ou indireto com diversas comunidades (SIMÕES et al., 2011).

Em Ubatuba - SP, mais de $80 \%$ do território é coberto pela Floresta Atlântica, sob a proteção do Parque Estadual da Serra do Mar (PESM) (BARBOSA et al., 2010). A UC é de proteção integral, ou seja, não permite

\footnotetext{
1 A Revolução Verde impôs um processo de homogeneização modernizadora da prática agrícola ao redor do mundo (CAPORAL, 2009), acabando com a cultura e os conhecimentos locais de diversas comunidades rurais, por meio da mecanização, da monocultura, das sementes híbridas e geneticamente modificadas e sua ciência cartesiana (CAPORAL, 2009). Os mais afetados foram os agricultores familiares devido aos altos investimentos e à necessidade de grandes porções de terra para a prática ser rentável.

2 Hotspots são ecossistemas de enorme biodiversidade, com diversas espécies endêmicas tanto animais quanto vegetais, que estão sendo degradados a ponto de ameaçar a continuidade da reprodução das espécies que ali ocorrem (GUEDES et al., 2005). Myers et al. (2000) classificam hotspots como áreas com concentrações excepcionais de espécies endêmicas e que enfrentam uma perda excepcional de habitat.
} 
que comunidades permaneçam em seus domínios (DIEGUES, 2001). O município guarda rica história cultural, formada por diversas comunidades tradicionais, entre elas caiçaras, quilombolas e indígenas e algumas comunidades rurais de agricultores familiares (OTANI et al., 2011). Em grande parte, os membros das comunidades tradicionais são agricultores-pescadores que vivem em relação íntima com o ecossistema, beneficiando-se de seus bens e serviços (DIEGUES, 2001). Muitas dessas comunidades se encontram dentro dos limites do PESM (SILVA, 2008) e enfrentam as restrições impostas pela legislação da UC, como proibição da pesca, da caça e do extrativismo, além de impedir a agricultura de queima e corte tradicional da região (BARBOSA et al., 2010). Esse panorama tem dificultado a permanência dessas famílias em seus territórios originais e causado conflitos com as diretrizes do PESM (SIMÕES et al., 2011).

As áreas naturais geram diversos serviços e bens para o bem-estar humano, os quais podem ser chamados de serviços ecossistêmicos (FAGERHOLM et al., 2012). Assim, serviços ecossistêmicos (SE) são os benefícios que as pessoas obtêm dos ecossistemas naturais (MEA, 2005). Serviços como a manutenção do ciclo da água e a purificação do ar, bens como matéria prima para construções e espécies medicinais são contribuições diretas ou indiretas dos ecossistemas para manter e enriquecer a vida humana (DE GROOT et al., 2002; CHAN et al., 2012; MÜLLER; BURKHARD, 2012).

Muitos estudos têm focado em avaliar a compreensão de agricultores acerca dos SE como ferramenta para construção de ações participativas para a conservação da natureza (SILVANO et al., 2008; BARRENA et al., 2014; MUHAMAD et al., 2014; BUQUERA, 2015). A categorização dos serviços facilita a apreensão da percepção dos agricultores, sendo a forma mais comum a divisão baseada em funções (DE GROOT et al., 2002; MEA, 2005; HEIN et al., 2006).

Este trabalho emprega a classificação proposta por De Groot et al. (2002). De acordo com esses autores, a função de regulação mantém processos ecológicos e sistemas de suporte da vida, gerando serviços como a limpeza da água e do ar, solos sadios, clima favorável, entre outros; a função de habitat provê espaço habitável para todas as espécies animais e vegetais e seus serviços são a conservação da biodiversidade e a reprodução da vida que suporta as funções ambientais; a função de produção refere-se aos produtos obtidos diretamente da natureza, os serviços ecossistêmicos originados são alimentos, combustíveis, fibras, recursos medicinais, etc. Por último, a função de informação inclui o senso de bem-estar ligado a experiências com o ambiente natural gerando serviços que proporcionem o enriquecimento espiritual, a recreação, oportunidades para pesquisa, entre outros (DE GROOT et al., 2002).

As percepções de membros de um grupo cultural podem ser avaliadas por meio de duas abordagens. A investigação êmica procura entender determinada cultura com base nela própria, a partir do ponto de vista dos membros dessa comunidade (ROSA; OREY, 2012). Já a outra abordagem, a ética, é a interpretação descritiva do que cada cultura representa, a partir de um olhar de fora da comunidade (AMOROZO et al., 2002). Dessa forma, uma metodologia que avalie o ponto de vista êmico para posteriormente o descrever de maneira ética pode ser o retrato mais fiel das percepções de determinados membros de uma comunidade.

Diante do exposto, a percepção de SE de comunidades rurais localizadas em áreas florestais ameaçadas pode demonstrar o valor que estas dão á conservação do ecossistema que as circunda (SANDHU et al., 2007; LAMARQUE et al., 2011). A partir desse conhecimento, e por meio de construções participativas, é possível traçar ações de conservação coerentes com as realidades locais (VODOUCHÊ et al., 2010; RODRIGUES et al., 2012).

Entender como agricultores valoram e manejam a natureza demonstra sua atuação frente à necessidade de renovação constante para a continuidade da família e do seu meio de reprodução (GOMES; TUBALDINI, 2005; TOLEDO; BARRERA-BASSOLS, 2009). Dessa maneira, integrar tais agentes em projetos de conservação de ecossistemas, principalmente aqueles ameaçados, pode resultar na proteção mais eficaz das áreas naturais e da cultura local (DIEGUES, s.d.). Considerando o exposto, o presente estudo teve por objetivo avaliar a percepção sobre os SE de agricultores familiares que praticam agricultura de base ecológica na região de Ubatuba-SP. 


\section{Material e Métodos}

\section{Caracterização do local de estudo}

O município de Ubatuba está situado no litoral norte do estado de São Paulo (23²6'02”S 4504'16”W), seu relevo é dominado por planície costeira, terminando na Serra do Mar, o clima é tropical úmido, sem estação seca, com precipitação média anual superior a $2.200 \mathrm{~mm}$ (CAMPOS, 2009).

As comunidades rurais estudadas situam-se nas regiões norte, centro e sul do município (Figura 1). Segundo Otani et al. (2011), elas apresentam diferentes origens culturais e formas de ocupação agrícola. O norte da cidade é o local onde se concentra a maioria das populações tradicionais de Ubatuba (BARBOSA et al., 2010) e é a mais restrita ao plantio pois insere-se sob os domínios do PESM. Caiçaras, quilombolas e indígenas cada qual possuem uma área de cultivo, com limites muitas vezes imaginários (VIANNA, 2008). Alguns dos agricultores dessas comunidades nunca utilizaram o pacote tecnológico da agricultura convencional, por isso suas roças e bananais são tratadas tradicionalmente, com práticas e saberes ancestrais (OTANI et al., 2011).

A região central é mais urbanizada e grande parte está fora da área de restrição da UC, apresentando extensões de terra mais planas que o sul e o norte, possibilitando aos agricultores mais áreas de cultivo (OTANI et al., 2011). Nessa localidade, grande parte dos produtores migrou de outros lugares e alterou suas práticas convencionais para agricultura de base ecológica, principalmente por experiências de intoxicação e demanda do mercado turístico por produtos orgânicos (BARBOSA et al., 2010). A região sul é a mais próxima de Caraguatatuba e São Paulo, sendo a porta

FIGURA 1: Mapa em miniatura da macro escala onde está inserida a região de estudo no território brasileiro (Fonte: $<$ https://pt.wikipedia. org/wiki/Ubatuba>); e mapa com as localizações dos bairros onde moram os agricultores entrevistados.

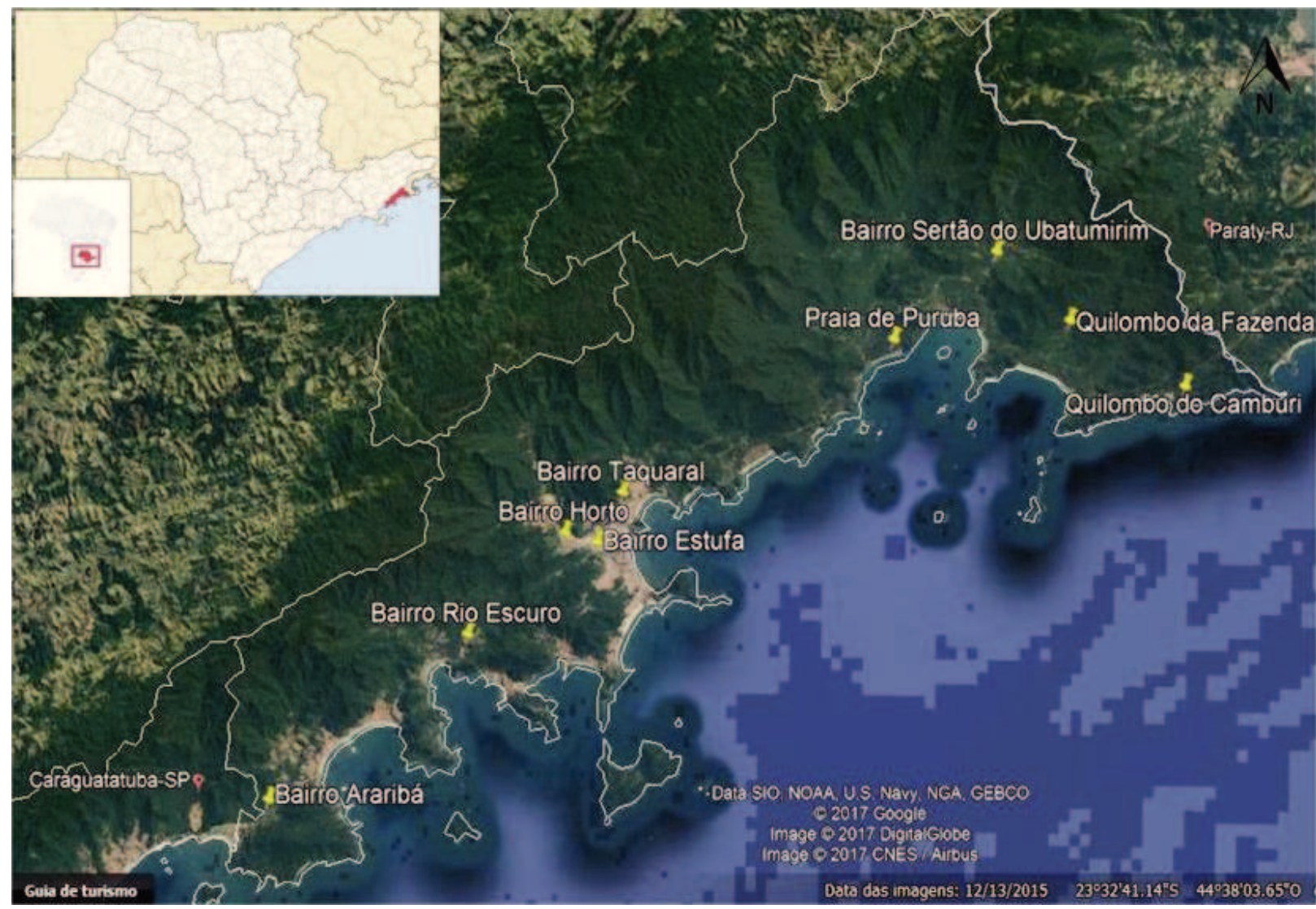

Fonte: Google Earth 
de entrada da especulação imobiliária e de pressões turísticas (PANNIZA, 2004).

Aproximadamente 125 propriedades rurais de Ubatuba são consideradas de agricultura familiar, possuindo até quatro módulos fiscais (CATI, 2015). Os agricultores familiares são aqueles que apresentam uma lógica de reprodução centrada na continuidade da família e na manutenção dos recursos, tais atores estão em contínua adaptação às pressões do mercado capitalista e da modernidade (WANDERLEY, 2003). Parte desses agricultores, como no centro do município, mudou para manejos baseados nos princípios agroecológicos por motivos de intoxicação e/ou demandas do mercado local e regional (OTANI et al., 2011). Na região sul, a maioria dos agricultores familiares é proveniente de outras cidades e se estabeleceu com o cultivo convencional de olerícolas.
Para o estudo foram selecionados 20 agricultores familiares entre os que praticam agricultura de base ecológica $^{3}$ (Tabela 1). A escolha dos agricultores ocorreu com base no conhecimento de técnicos dos diversos órgãos que atuam na Assistência Técnica e Extensão Rural (ATER) no município.

Os técnicos consultados pertencem a órgãos como o Instituto de Terras do Estado de São Paulo (ITESP), responsável pela assistência aos indígenas e quilombolas; a Coordenadoria de Assistência Técnica Integrada (CATI), que oferece diversos cursos e suporte para o desenvolvimento rural, com grande enfoque nos conceitos da agroecologia; a Agência Paulista de Tecnologias Agrícolas, que desenvolve estudos socioeconômicos, de produção e ambientais e adaptam tecnologias sociais para os agricultores; e a Secretaria

TABELA 1: Caracterização dos agricultores entrevistados com descrição da região, localidade e número de agricultores classificados em caiçara e quilombola (tradicionais $-\mathrm{T}$ ), imigrante ou descendente (não tradicionais $-\mathrm{NT}$ ) e agrupados por gênero $(\mathrm{M}=$ masculino; $\mathrm{F}=$ feminino), origem (rural $-\mathrm{R}$ ou urbana $-\mathrm{U}$ ), conhecimentos sobre as práticas tradicionais (PT) e conceitos da agroecologia (CA) e histórico de prática da agricultura convencional.

\begin{tabular}{|c|c|c|c|c|c|c|c|c|c|c|}
\hline \multirow[b]{2}{*}{ Região } & \multirow[b]{2}{*}{ Localidade } & \multirow[b]{2}{*}{ Classificação } & \multicolumn{2}{|c|}{ Gênero } & \multicolumn{2}{|c|}{ Origem } & \multicolumn{2}{|c|}{ Conhecimento } & \multirow{2}{*}{$\begin{array}{c}\text { Histórico } \\
\text { agricultura } \\
\text { convencional }\end{array}$} & \multirow[b]{2}{*}{ Total } \\
\hline & & & $\mathbf{M}$ & $\mathbf{F}$ & $\mathbf{R}$ & $\mathbf{U}$ & PT & CA & & \\
\hline \multirow{4}{*}{ Norte } & $\begin{array}{l}\text { Bairro Sertão do } \\
\text { Ubatumirim }\end{array}$ & Caiçara (T) & 5 & 4 & 9 & 0 & 9 & 7 & 0 & 9 \\
\hline & $\begin{array}{l}\text { Quilombos da Fazenda } \\
\text { e do Camburi }\end{array}$ & Quilombola (T) & 2 & 0 & 2 & 0 & 2 & 2 & 0 & 2 \\
\hline & Praia do Puruba & $\begin{array}{c}\text { Imigrante ou } \\
\text { descendente (NT) }\end{array}$ & 0 & 1 & 0 & 1 & 1 & 1 & 0 & 1 \\
\hline & & Total & 7 & 5 & 11 & 1 & 12 & 10 & $\mathbf{0}$ & 12 \\
\hline \multirow{3}{*}{ Centro } & $\begin{array}{c}\text { Bairros do Taquaral e } \\
\text { Horto }\end{array}$ & Caiçara (T) & 1 & 1 & 2 & 0 & 1 & 2 & 1 & 2 \\
\hline & Bairros Estufa e Horto & $\begin{array}{c}\text { Imigrante ou } \\
\text { descendente (NT) }\end{array}$ & 1 & 2 & 2 & 1 & 0 & 3 & 1 & 3 \\
\hline & & Total & 2 & 3 & 4 & 1 & 1 & 5 & 2 & 5 \\
\hline \multirow[t]{2}{*}{ Sul } & $\begin{array}{c}\text { Bairros Araribá e Rio } \\
\text { Escuro }\end{array}$ & $\begin{array}{c}\text { Imigrante ou } \\
\text { descendente (NT) }\end{array}$ & 2 & 1 & 3 & 0 & 1 & 2 & 3 & 3 \\
\hline & & Total geral & 11 & 9 & 18 & 2 & 14 & 17 & 5 & 20 \\
\hline
\end{tabular}

3 Cada vez mais há o surgimento de outras técnicas que não agridem o ambiente e a saúde humana (CAPORAL, 2009). São manejos embasados nos conceitos agroecológicos, biodinâmicos e da agricultura orgânica, entre outros (GLIESSMAN, 2002; ALTIERI; TOLEDO, 2011). Essas novas práticas vêm sido chamadas de agricultura de base ecológica, as quais têm ajudado a resgatar diversos saberes hereditários que haviam sido perdidos nas comunidades rurais (GLIESSMAN et al., 2007; CAPORAL, 2009). Tais processos somente são eficazes com a construção participativa das diretrizes a serem seguidas (CAMARGO, 2007). 
Municipal de Agricultura, Pesca e Abastecimento, que fornece diversos subsídios como o empréstimo de máquinas. Todos esses órgãos interagem entre si e vêm atuando nos últimos anos no fortalecimento das agricultura de base ecológica, disseminando e embasando a perspectiva agroecológica entre os agricultores do município. Os agricultores escolhidos foram aqueles que melhor representam o conjunto de agricultores que trabalham com agricultura de base ecológica em Ubatuba. Tal representatividade foi indicada pelos técnicos dos órgãos citados.

$\mathrm{O}$ efeito da origem dos entrevistados foi avaliado considerando-se os agricultores caiçaras e quilombolas como tradicionais $(\mathrm{T})$, ou seja, aqueles que descendem e ainda participam das comunidades tradicionais de Ubatuba-SP. Os demais foram classificados como não tradicionais (NT), e agrupam aqueles que se mudaram de outras regiões, como Paraná ou interior de São Paulo, ou os naturais de Ubatuba, porém descendentes de comunidades externas ao município, como os japoneses.

\section{Construção do processo de avaliação} da percepção de serviços ecossistêmicos

Inicialmente, ferramentas do método MESMIS (Marco para Avaliação de Sistemas de Manejo de Recursos Naturais Incorporando Indicadores de Sustentabilidade), propostas por Masera et al. (1999), foram empregadas no estabelecimento de indicadores da percepção de SE. Para tanto, realizou-se revisão bibliográfica sobre o local de estudo e o tema em questão, possibilitando a elaboração da entrevista semiestruturada (DALMORA, 2004).

A entrevista abordou certos pontos como a trajetória de vida do informante e de sua família, o histórico da propriedade e dos manejos agrícolas utilizados, bem como as práticas de conservação dos recursos aplicadas pelo agricultor. Durante as visitas, inicialmente era explicado qual o objetivo do trabalho e seu tema, a partir desse ponto o agricultor tinha total liberdade para falar sem ser interrompido a todo o momento. A pesquisadora somente realizava perguntas mais direcionadas quando os pontos de maior relevância para o estudo não eram alcançados. As entrevistas foram gravadas para posterior transcrição. Em determinado momento da visita era realizada uma caminhada ao longo das diversas áreas do quintal agroflorestal ou da área de produção. A caminhada foi adaptada da caminhada transversal de Verdejo (2006). Assim, foi possível conhecer os cultivos e áreas florestadas, bem como os manejos realizados. Esse trajeto também foi gravado para posterior transcrição.

Todas as falas dos agricultores foram analisadas por meio de abordagem êmica, e então sistematizadas, por meio de abordagem ética, empregando-se como base a classificação de De Groot et al. (2002) para identificar SE mencionados pelos agricultores nas entrevistas. A seguir, foram classificados e definidos os indicadores de cada serviço ecossistêmico e estabelecido o protocolo de SE e indicadores para avaliação da percepção com base no que foi obtido em todas as entrevistas.

Para avaliar a percepção dos SE de cada agricultor, as entrevistas foram reanalisadas e, para cada indicador constante no protocolo, foram atribuídas notas, sendo: nota zero - não citado pelo entrevistado; nota 1 - apenas citado ou mencionado; nota 2 - citado e demonstrado conhecimento; nota 3 - demonstração de conhecimento, apresentando conceitos e informações.

As notas atribuídas aos indicadores dos SE foram plotadas na matriz indicador $\mathrm{x}$ agricultor. A seguir, esta foi utilizada para determinar a similaridade de respostas entre os agricultores empregando-se a análise de agrupamento hierárquico no método de UPGMA, utilizando-se Bray-Curtis como medida de ligação e considerando-se o maior ajuste cofenético. A linha de corte para identificação dos grupos similares foi definida de maneira que somente os agrupamentos abaixo de $50 \%$ da distância total fossem considerados (GOTELLI; ELLISON, 2011).

A percepção de SE de cada agricultor foi estimada para cada uma das funções dos ecossistemas calculandose o Índice de Consolidação da Percepção Ecossistêmica (ICPE) obtido pela fórmula: 


\section{$\mathrm{ICPE}=\frac{\Sigma \text { notas dos indicadores }-\mathrm{n}^{\mathrm{o}} \text { de indicadores }}{\left(\mathrm{n}^{\mathrm{o}} \text { de indicadores }\right)^{\star}\left(\Sigma \mathbf{n}^{\mathrm{o}} \text { de parâmetros por indicador }\right)}$}

Inicialmente foi calculado o valor máximo do ICPE obtido a partir da atribuição da nota 3 a todos os indicadores $\left(\mathrm{ICPE}_{\max }\right)$. A seguir, foi calculado o ICPE de cada agricultor considerando as notas atribuídas para cada indicador em todas as funções e estimado o percentual que este valor representou em relação ao valor máximo. Esse resultado representa o valor relativo da percepção de cada agricultor em relação aos SE percebidos por todos os agricultores entrevistados. Com o objetivo de avaliar a percepção dos dois grupos de origem (T e NT), foi calculado o ICPE referente às notas de todos os indicadores de cada função $\left(\mathrm{ICPE}_{\mathrm{Reg}}\right.$; $\mathrm{ICPE}_{\text {Habt }} ; \mathrm{ICPE}_{\text {Prod }} ; \mathrm{ICPE}_{\text {Inf }}$ ). O nível de percepção de cada agricultor ou função foi considerado como alto quando acima de $75 \%$ em relação ao $\mathrm{ICPE}_{\max }$, médio quando $50 \%<\mathrm{ICPE}_{\max }<75 \%$, baixo quando $25 \%<\mathrm{ICPE}_{\max }$ $<50 \%$ e incipiente quando inferior a $25 \%$ do $\mathrm{ICPE}_{\max }$.
Para verificar se houve diferença na percepção entre os agricultores tradicionais e não tradicionais, foi realizada a análise não paramétrica de KruskalWallis com base nas notas atribuídas. Todas as análises estatísticas realizadas foram efetuadas no programa PAST 3.02 (HAMMER et al., 2001).

\section{Resultados}

O protocolo de SE e indicadores permitiu identificar $36 \mathrm{SE}$ citados pelos agricultores e a construção de 31 indicadores (Tabela 2). Os serviços identificados corresponderam ao conceito científico de serviços ecossistêmicos (SILVANO et al., 2005).

TABELA 2: Serviços ecossistêmicos identificados nas entrevistas dos agricultores e seus respectivos indicadores, agrupados de acordo com o descritor da função ao qual pertencem bem como da função do ecossistema segundo conceitos de De Groot et al. (2002).

\begin{tabular}{|c|c|c|c|}
\hline Função & Descritor da Função & Serviços Ecossistêmicos percebidos & Indicadores \\
\hline \multirow{16}{*}{ 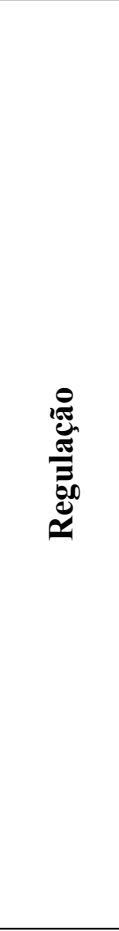 } & Regulação gasosa & Ar puro e limpo & Qualidade do ar \\
\hline & \multirow{2}{*}{ Regulação Climática } & Manutenção da temperatura e de precipitações & Clima favorável para agricultura \\
\hline & & Estabilidade do clima & Mudanças climáticas \\
\hline & Prevenção de distúrbios & $\begin{array}{l}\text { Manutenção da continuidade da prática } \\
\text { agrícola }\end{array}$ & $\begin{array}{l}\text { Capacidade de regeneração da } \\
\text { Floresta Atlântica }\end{array}$ \\
\hline & \multirow{3}{*}{$\begin{array}{l}\text { Regulação da água/ } \\
\text { Suprimento de água }\end{array}$} & Manutenção da irrigação natural & \multirow{2}{*}{ - Manutenção de água } \\
\hline & & Regulação do fluxo hídrico & \\
\hline & & Suprimento para o consumo & Qualidade de água \\
\hline & \multirow{3}{*}{$\begin{array}{l}\text { Retenção de solo/ } \\
\text { Formação de solo }\end{array}$} & Estabilidade do solo & \multirow{2}{*}{ Manutenção de solo } \\
\hline & & Prevenção da erosão & \\
\hline & & Manutenção da produtividade & Qualidade de solo \\
\hline & \multirow{2}{*}{ Ciclagem de nutrientes } & Manutenção de solos saudáveis e férteis & $\begin{array}{l}\text { Manutenção da ciclagem de } \\
\text { nutrientes }\end{array}$ \\
\hline & & Solo vivo & $\begin{array}{l}\text { Elementos naturais que incorporam } \\
\text { nutrientes }\end{array}$ \\
\hline & Tratamento do desperdício & Filtragem da água & Funções da mata ciliar \\
\hline & \multirow{2}{*}{ Polinização } & $\begin{array}{l}\text { Atração de polinizadores selvagens por } \\
\text { especies vegetais }\end{array}$ & Espécies melíferas \\
\hline & & $\begin{array}{l}\text { Dependência da agricultura da polinização } \\
\text { natural }\end{array}$ & Espécies polinizadoras \\
\hline & Controle biológico & $\begin{array}{l}\text { Ecossistemas controlam potenciais pestes e } \\
\text { doenças }\end{array}$ & $\begin{array}{l}\text { Controle biológico de pragas e } \\
\text { doenças }\end{array}$ \\
\hline
\end{tabular}




\begin{tabular}{|c|c|c|c|}
\hline Função & Descritor da Função & Serviços Ecossistêmicos percebidos & Indicadores \\
\hline \multirow{2}{*}{ 离 } & Função de refúgio & Manutenção da biodiversidade animal & $\begin{array}{l}\text { Abrigo e alimento para animais } \\
\text { silvestres }\end{array}$ \\
\hline & Função de berçário & $\begin{array}{l}\text { Reprodução da vida que suporta as funções } \\
\text { ambientais }\end{array}$ & Manutenção da vida \\
\hline \multirow{8}{*}{ 异 } & \multirow{2}{*}{$\begin{array}{l}\text { Produção de frutos, grãos } \\
\text { e hortaliças }\end{array}$} & Alimentos & Garantia de nutrição familiar \\
\hline & & Elementos da natureza para alimentação & Fonte de alimentos \\
\hline & Matéria-prima & Madeira e fibras para construção e produção & Fonte de matéria-prima \\
\hline & \multirow{2}{*}{ Recursos genéticos } & Manutenção da produtividade de cultivares & \multirow{2}{*}{ - Adaptação das espécies } \\
\hline & & Seleção natural dos indivíduos mais adaptados & \\
\hline & \multirow{2}{*}{ Recursos medicinais } & Manutenção da saúde & \multirow{2}{*}{ Uso dos saberes tradicionais } \\
\hline & & Fonte de ervas medicinais & \\
\hline & Recursos ornamentais & Decoração & Fonte de recursos ornamentais \\
\hline \multirow{10}{*}{ 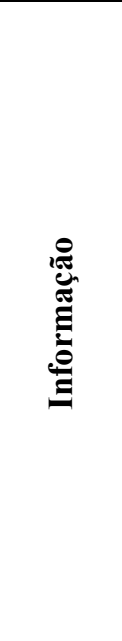 } & Informação estética & Possibilidade de contemplação & Fonte de belezas naturais \\
\hline & \multirow{2}{*}{ Recreação e ecoturismo } & $\begin{array}{l}\text { Possibilidade de caminhadas no ambiente } \\
\text { natural }\end{array}$ & Recreação \\
\hline & & $\begin{array}{l}\text { Aumento da procura por locais onde há } \\
\text { contato com a natureza }\end{array}$ & Turismo rural \\
\hline & \multirow{2}{*}{$\begin{array}{l}\text { Inspiração cultural e } \\
\text { artística }\end{array}$} & $\begin{array}{l}\text { Expressões culturais e artísticas passadas } \\
\text { através das gerações }\end{array}$ & Saberes tradicionais \\
\hline & & Elementos e inspiração para produção artística & Produção de artesanato \\
\hline & \multirow{3}{*}{$\begin{array}{l}\text { Informação espiritual e } \\
\text { histórica }\end{array}$} & Satisfação com o lugar onde vive & \multirow{2}{*}{ - Bem-estar e qualidade de vida } \\
\hline & & Satisfação em trabalhar com a natureza & \\
\hline & & $\begin{array}{l}\text { Conhecimentos e manejos tradicionais } \\
\text { transmitidos oralmente }\end{array}$ & Saberes hereditários \\
\hline & \multirow{2}{*}{$\begin{array}{l}\text { Informação científica e } \\
\text { educacional }\end{array}$} & $\begin{array}{l}\text { Oportunidades para estudo e novos } \\
\text { aprendizados }\end{array}$ & Busca por informação \\
\hline & & Áreas para pesquisas ambientais & Participação em pesquisas \\
\hline
\end{tabular}

A análise de similaridade das respostas gerou a formação de quatro grupos principais (Figura 2). O primeiro (A) foi constituído exclusivamente pela agricultora S2-NT, que se diferenciou de todos os outros agricultores, tendo como cultivo principal a monocultura de gengibre certificada por auditoria. A propriedade dessa agricultura apresentou mais características de microempresa do que de empreendimento familiar.

O segundo grupo (B) foi formado por dois agricultores tradicionais (N8-T e N10-T), sendo que ambos demonstraram pouco conhecimento acerca dos SE gerados pela Floresta Atlântica e sobre os próprios processos e funcionamento da agricultura ecológica. O agricultor N8-T afirmou que "Eles dizem que é importante a árvore na beira da cachoeira, eu acho que não,..., se você cortar uma árvore dessa ai você vai tirar uns 4 ou 5 litros de água dela, se ela não morrer,..., ela não vai mandar essa água de volta.".
O terceiro agrupamento (C) foi constituído por quatro agricultores, a maioria não tradicional, moradores das regiões centro e sul. Estes produzem prioritariamente espécies olerícolas direcionados ao mercado e apresentaram histórico de prática da agricultura convencional anterior ao uso de métodos de base ecológica, os quais se concentram na substituição de insumos. A razão da transição é unânime em todos os casos, como explicou o agricultor C4 - NT: “...logo que eu comecei a trabalhar nessa terra, me intoxiquei com agrotóxico... Aí parei com o veneno, nunca mais...".

Por fim, o grupo (D) foi composto pelos demais entrevistados, a maioria residente da região norte do município e de origem tradicional. No geral possuem cultivos diversificados com baixa utilização de insumos e demonstraram conhecimento maior dos serviços providos pelo ecossistema local. Três agricultores, que apareceram nesse mesmo agrupamento, sendo um do 
FIGURA 2: Dendrograma resultante da análise de agrupamento (UPGMA/Bray Curtis, Coeficiente cofenético de 0,8395) baseado nas notas atribuídas à percepção dos serviços ecossistêmicos de acordo com as entrevistas realizadas ( $\mathrm{n}=20$ agricultores).

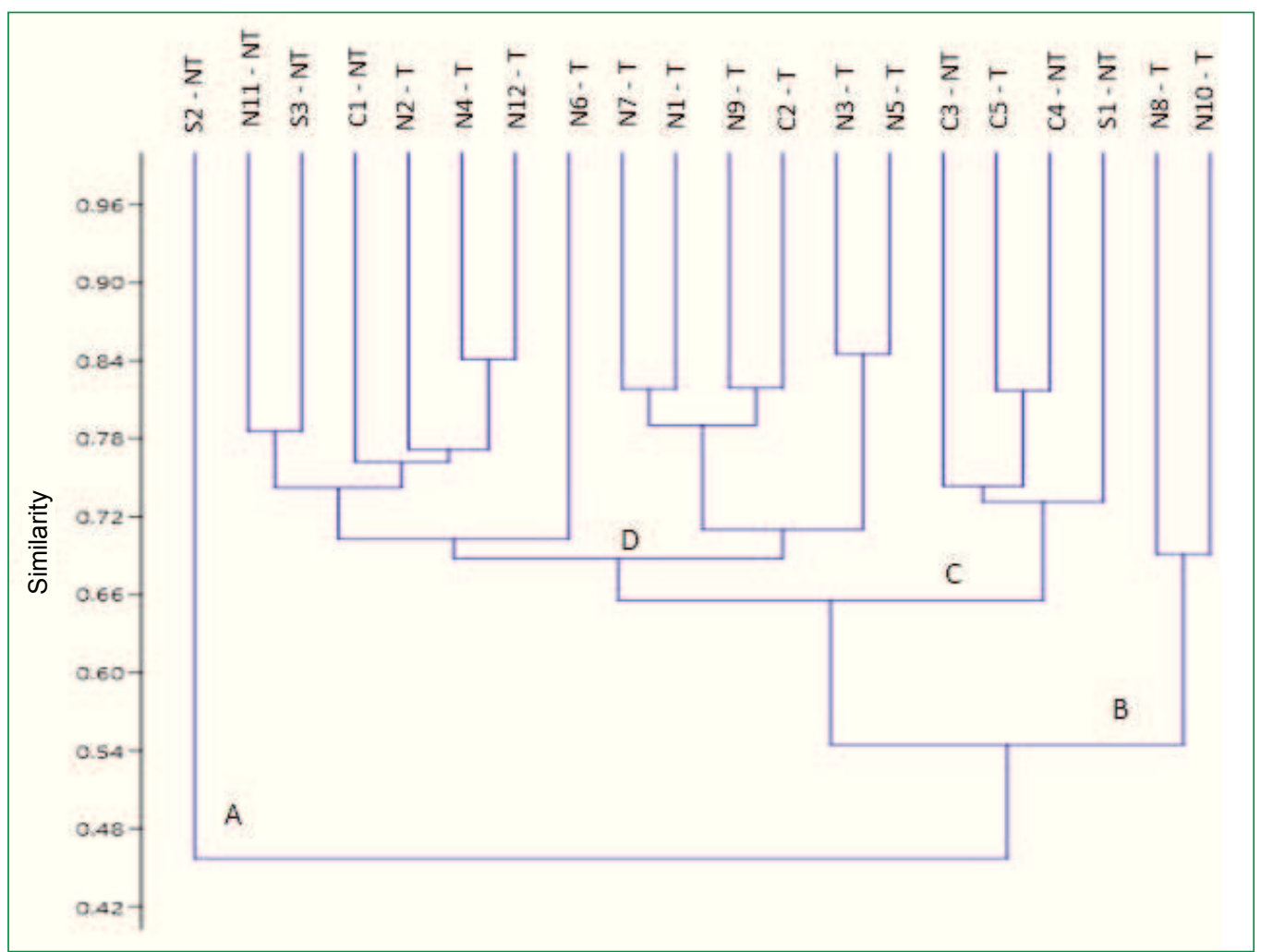

sul do município, S3 - NT, e dois da região central, C1 - NT e C2 - T, apresentaram características similares aos agricultores do norte em suas entrevistas. Essas similaridades estão presentes em seus manejos e cultivos, bem como no modo de vida, o que pode demonstrar a razão de se encontrarem no mesmo grupo.

No conjunto das respostas apresentadas pelos agricultores não houve separação nítida da percepção dos SE em relação à região em que habitam, uma vez que a maioria deles (grupo D) apresentou agricultores tanto das zonas mais urbanizadas (centro e sul) quanto da mais conservada (norte). Por outro lado, no grupo B ambos os agricultores se situam na região norte, enquanto no grupo $\mathrm{C}$ predominaram agricultores das regiões mais urbanizadas.

De maneira geral, 90\% dos agricultores apresentaram percepção incipiente dos serviços gerados pelas funções do ecossistema (Figura 3 ). Os agricultores que se destacaram foram C2 e N9, pertencentes ao grupo dos tradicionais, que alcançaram respectivamente $50 \%$ e 55\% do valor do $\mathrm{ICPE}_{\max }$ (Figura 3). Esses agricultores apresentaram alta similaridade em suas respostas, formando um subgrupo dentro do quarto agrupamento (D) (Figura 2). Por sua vez, as agricultoras N10 (T), S2 (NT) e C3 (NT) tiveram resultados de ICPE negativos (Figura 3), o que significa que não demonstraram percepção sobre a maioria dos $\mathrm{SE}$ em relação aos demais agricultores entrevistados. Ao se relacionar o resultado do ICPE das três agricultoras com a análise de similaridade é possível perceber que estas se encontram fora do agrupamento dos agricultores que apresentaram maior conhecimento sobre o ecossistema local (D) (Figura 2).

Com relação aos grupos de origem, os agricultores tradicionais demonstraram tendência a possuir, em média, maior percepção dos serviços gerados pelas funções de produção e informação em relação aos não tradicionais, excetuando-se apenas a função de habitat na qual ambos apresentaram baixo valor de ICPE $_{\text {Habt }}$ (Figura 4). Por outro lado, os agricultores não tradicionais 
FIGURA 3: Resultado do ICPE de cada agricultor tradicional e não tradicional. Entre parênteses a porcentagem do valor do ICPE em relação ao valor máximo possível (ICPEmax $=248)$

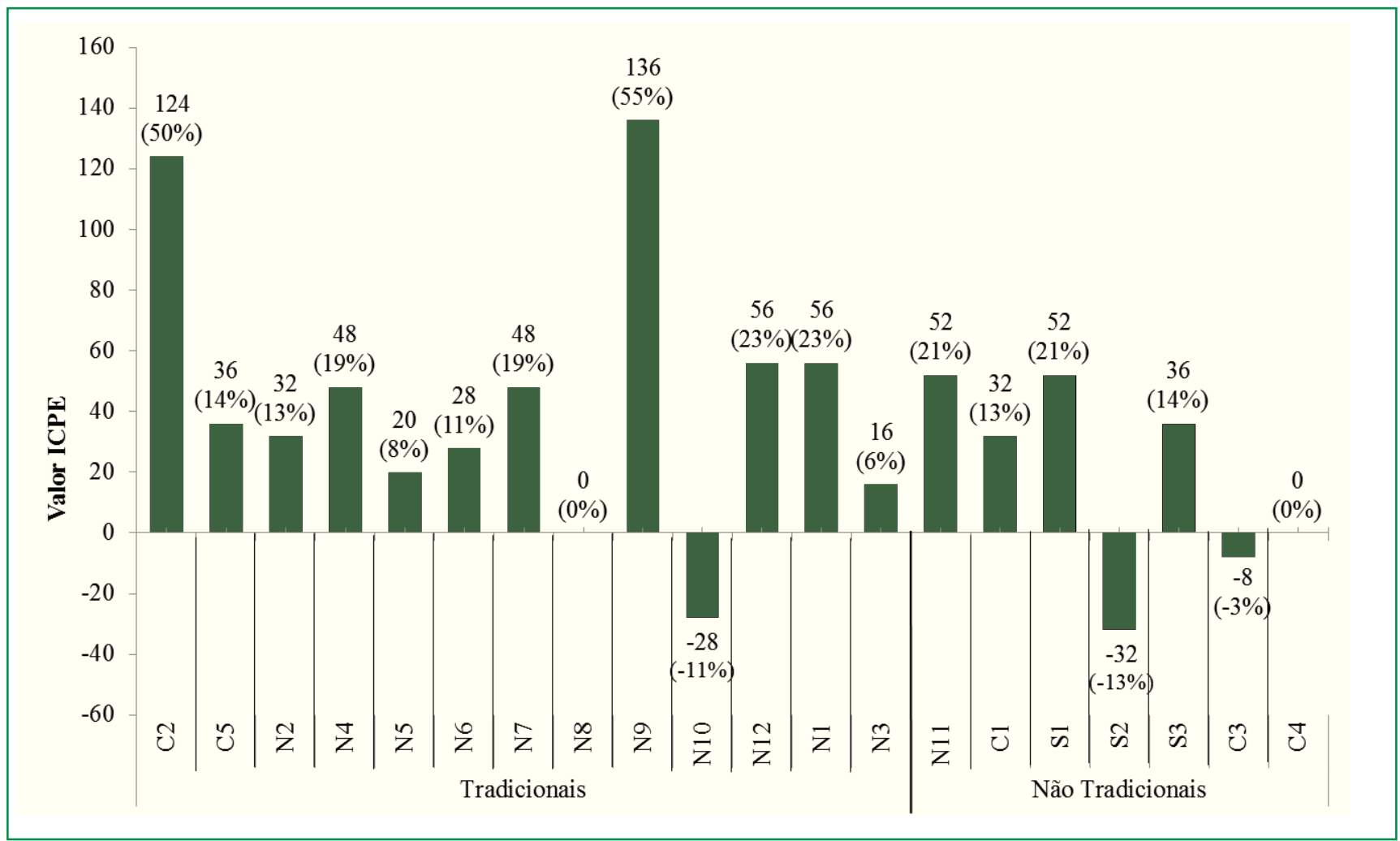

apresentaram tendência de maior percepção quanto aos serviços fornecidos pela função de regulação. Apesar dessas diferenças, o teste de Kruskal-Wallis demonstrou não haver diferença significativa $\left(\chi^{2}=0,66 ; p=0,41\right)$ entre as percepções de agricultores tradicionais e não tradicionais. A pouca expressão da diferença significativa pode ser explicada pela grande variação do ICPE dentro de cada grupo, ou pelo reduzido número de agricultores não tradicionais entrevistados (Figura 3). Portanto, a origem dos agricultores não foi o único fator para explicar a diferença de percepção dos SE entre eles, embora mostre tendências.

Para ambos os grupos de origem, foi possível notar a dominância da incipiente percepção quanto aos serviços provenientes da função de habitat, em especial para os agricultores não tradicionais (Figura 4). As falas mais citadas com relação a essa função foram "...os pássaros, gambás, pacas se alimentam de frutos..." e "... aqui a gente tira dois cachos [da juçara] e deixa um pros passarinhos...". O que evidencia que há conhecimento do serviço de áreas para alimentação da fauna, citado por $30 \%$ dos agricultores.

Por outro lado, $60 \%$ dos agricultores perceberam os serviços da função de produção. Os quais foram ressaltados pelas falas: "...a gente come o que produz...", “...hoje tá (sic) ali a mata fechada,..., mesmo que eu não plantei nada,..., dentro dela vai ter algum pé de árvore que vai me dar uma fruta pra eu me alimentar." e "...e é uma madeira que cresce, morre, seca, caiu, você vai lá, pega e faz lenha...".

Os serviços provenientes das funções de regulação e de informação foram os mais percebidos tanto por agricultores tradicionais quanto por não tradicionais. Com relação à função de regulação, foram frequentes falas como "...a mata produz água em abundância...", "...onde tem folha não compacta a terra...", "...se você planta a couve ali, o pulgão arregaça com tudo, se você planta outro tipo que o pulgão não gosta, ele já não vai mais ali."; e frases do tipo "...diversão é andar no meio 
FIGURA 4: Resultado do ICPE de cada função dos ecossistemas: regulação ( $\operatorname{ICPE}_{\text {Reg }}$ ), habitat ( $\operatorname{ICPE}_{\text {Habt }}$ ), produção (ICPE $\mathrm{Prod}$ ) e informação $\left(\mathrm{ICPE}_{\mathrm{Inf}}\right)$ calculadas para os dois grupos de origem, agricultores tradicionais (T) e não tradicionais (NT). Entre parênteses a porcentagem do valor do ICPE em relação ao valor máximo possível de ser alcançado se o agricultor tivesse recebido a nota 3 em todos os indicadores de serviços ecossistêmicos em cada uma das quatro funções dos ecossistemas (ICPEreg $\max _{\max }=112$; ICPEhabt $_{\max }=16$ ICPEprod $_{\max }=48 ;$ ICPEinf $_{\max }=72$ ).

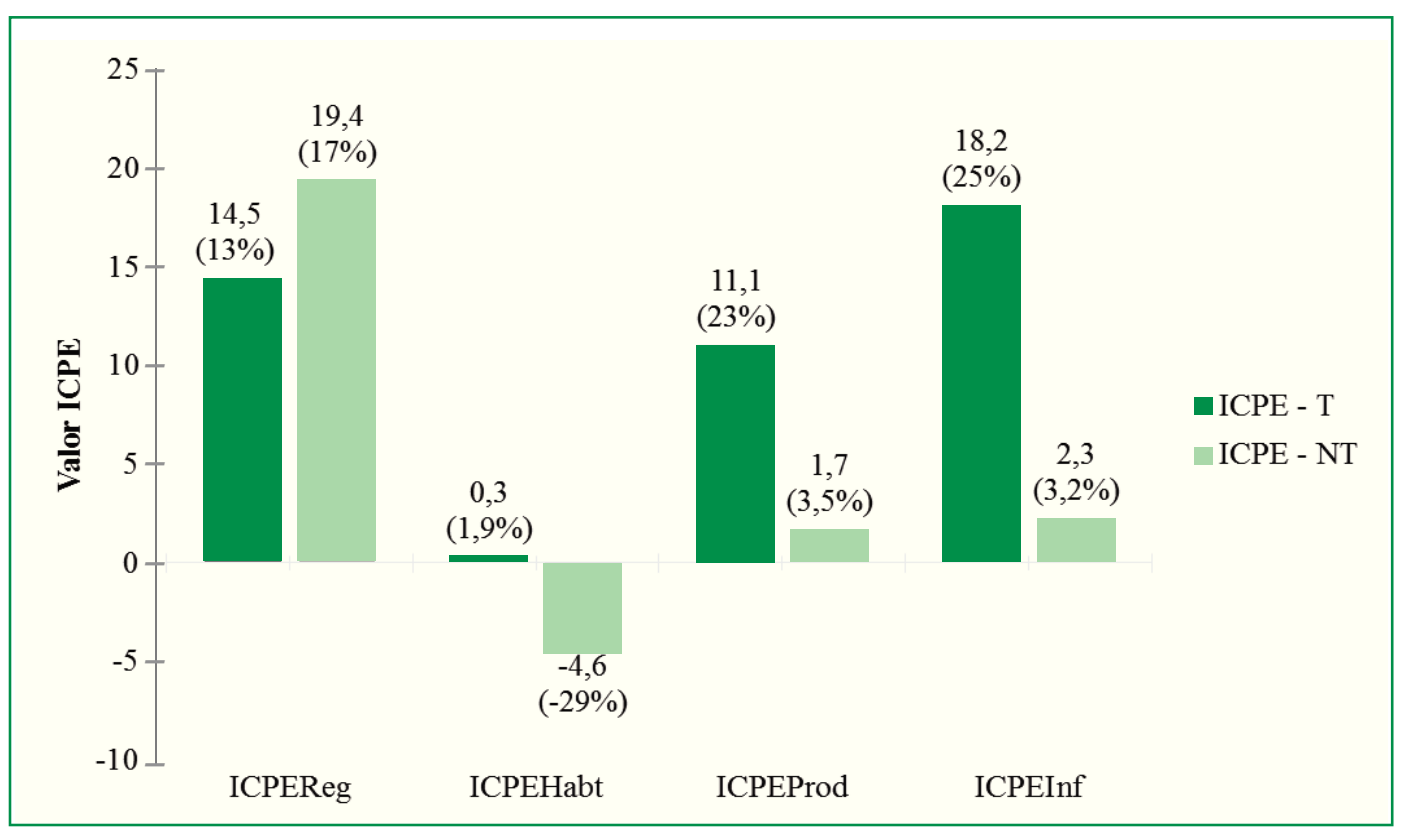

da mata, ir na cachoeira...", "...coisa mais linda que tem é a natureza..." e "... a permanência dos caiçaras mantêm o lugar...", referentes à função de informação.

\section{Discussão}

A relação das pessoas com o meio em que convivem tende a ser mais forte quando estas se mantêm no mesmo lugar onde nasceram, assim possuem maior familiaridade com o local e seus recursos e percebem melhor os SE do que aquelas que se mudaram há pouco tempo (MUHAMAD et al., 2014). Entretanto, no presente estudo, a percepção de SE dos agricultores tradicionais e não tradicionais não diferiram significativamente entre si. Isto pode ser atribuído às experiências pessoais, as quais podem influenciar em maior ou menor grau a percepção dos serviços (LOVATTO et al., 2008). Toledo e Barrera-Bassols (2009) colocam que um só informante carrega em sua bagagem cultural as experiências acumuladas na coletividade a qual pertence, iniciando no núcleo familiar, passando pela comunidade rural, pelo território e, por fim, pelo grupo cultural. Assim, cada agricultor pode apresentar uma determinada percepção de acordo com o conhecimento que adquiriu ao longo de suas vivências diárias individuais e coletivas.

Historicamente, há em Ubatuba de um lado grande pressão para o crescimento urbano e turístico (BARBOSA et al., 2010) e, de outro, as limitações de expansão urbana e agrícola trazidas pela criação do PESM (ADAMS, 2002; SIMÕES et al., 2011). Estes podem ter sido pontos relevantes para a pouca percepção de SE encontrada nas comunidades estudadas e representa fator grave para a conservação da área de Floresta Atlântica. Segundo Abram et al. (2014), o panorama apresentado pode ocasionar a dissociação da relação e da dependência das comunidades rurais com o ambiente, levando à perda da percepção dos SE.

Ao contrário do presente estudo, outros trabalhos, tanto em Ubatuba quanto em áreas similares, apontam para o vasto conhecimento sobre o ambiente natural de membros de comunidades rurais e tradicionais. Hanazaki et al. (2000), ao avaliarem duas comunidades de Ubatuba, concluíram que estas apresentaram amplo 
conhecimento sobre a diversidade de plantas nativas e exóticas. O mesmo ocorreu no estudo de Brito e SennaVale (2012), com caiçaras da praia do Sono no Rio de Janeiro.

Entretanto, ambos os autores concluem que parece ocorrer a perda do conhecimento tradicional sobre a diversidade de plantas nos locais estudados. E o motivo dessa perda é atribuído ao aumento do turismo, bem como às limitações de uso dos recursos das UC as quais as comunidades estão submetidas (HANAZAKI et al., 2000; BRITO; SENNA-VALE, 2012). Para mudança desse panorama é preciso que as diretrizes das UC incorporem a cultura dessas comunidades por meio de planejamentos participativos (BORGES; PEIXOTO, 2009; PILLA; AMOROZO, 2009).

Porém, alguns pontos positivos foram observados. Os agricultores C2-T e N9-T apresentaram a maior percepção observada, que está relacionada a diversas práticas agrícolas ecológicas e conservacionistas. Tais características podem ser observadas nas seguintes falas: "As pessoas dizem que a água não vai acabar, ela vai acabar sim..." e "A natureza dá tudo para o nosso bemestar, se não tiver a natureza você morre rapidinho..." do agricultor N9-T; e "Porque você trabalhar com a natureza é uma questão de observação, tem que observar, como que ela se manifesta... Porque não adianta eu colocar um pé de árvore aqui, porque se eu for ver na natureza, junto dela nasce outra, nos galhos dela nascem outras, então é um conjunto..." da agricultora C2-T. São atributos associados a atores-chave de processos de implantação de ações voltadas para a conservação de ecossistemas (SILVANO et al., 2008; MAFRA; STADLER, 2009). Dessa forma, a partir da identificação desses atores, tornam-se possíveis ações coletivas entre agricultores para incentivar a troca de informações e aprendizados (COSTABEBER; MOYANO, 2000). Essa prática permite que tais características associadas aos atores-chave se difundam entre os demais agricultores (SABOURIN et al., 2014; SANTOS et al., 2014).

É importante ressaltar que os agricultores, como elementos centrais do processo, devem participar ativamente da escolha das práticas a serem introduzidas (GLIESSMAN et al., 2007; PACÍFICO; SOGLIO, 2010). Da mesma forma, é preciso que os técnicos respeitem o conhecimento tradicional, ao inovar participativamente unindo conhecimentos científicos com os saberes tradicionais (ALTIERI; TOLEDO, 2011; COLLADO et al., 2013). Constatou-se durante a entrevista que todos os agricultores recebem ATER de alguns dos órgãos governamentais citados, além do trabalho de extensão realizado pelo Instituto de Permacultura e Ecovilas da Mata Atlântica (IPEMA). As ações têm dado resultados como a formação de grupos de certificação orgânica participativa, a "Rede Agroecológica Caiçara", para a comercialização direta de produtos, o Projeto Juçara para recuperação da palmeira nativa e criação de renda, entre outros. Assim, evidencia-se a necessidade de um olhar mais atento das atividades de ATER na introdução de novas práticas, criadas de forma participativa, que ressaltem a relação direta entre a Floresta Atlântica e as áreas de cultivo, visando à manutenção da prática agrícola (SILVANO et al., 2005; SWINTON et al., 2007).

Quanto às funções do ecossistema, houve baixa percepção de serviços fundamentais como os gerados pela função de habitat. Em estudo realizado no Rio Grande do Sul, agricultores familiares reconheceram, entre as principais funções do ecossistema, o fato deste servir de moradia para espécies animais e vegetais, bem como para sua sobrevivência (MARTINEZ et al., 2013). O único serviço percebido pelos $30 \%$ dos agricultores de Ubatuba estudados que citaram a função de habitat foi com relação à floresta prover os alimentos para os animais. Esse resultado pode refletir a dificuldade dos agricultores em extrapolar os serviços que a natureza pode oferecer para locais mais distantes de suas moradias (SWINTON et al., 2007).

Por outro lado, houve maior percepção dos serviços provenientes da função de regulação, principalmente por serem serviços ligados mais diretamente à prática agrícola. Ao notar tais serviços, os agricultores estudados demonstram sua capacidade de uso múltiplo do território (CARNEIRO, 1998). Evidencia-se que esses agentes têm conhecimento dos fatores que influenciam diretamente na agricultura, assim, se utilizam da multifuncionalidade como uma das estratégias para a sobrevivência familiar (RUA, 2005). Campos et al. (2011) encontraram resultados similares, nos quais os 
agricultores reconheceram a importância da água e da fertilidade do solo como SE fundamentais.

No entanto, os agricultores de Ubatuba estudados pouco perceberam a relação de suporte e proteção em longo prazo, a qual pode existir entre a floresta e áreas de cultivo (MUHAMAD et al., 2014). Foram pouco citados os SE referentes à sustentação do ecossistema natural (De GROOT et al., 2002). Essa forma de percepção, de acordo com Swinton et al. (2007), evidencia que os agricultores não visualizam a aplicação dos serviços indiretos que o ecossistema natural pode propiciar para a produção agrícola.

Apesar das diferenças individuais, a função de informação foi quase unânime no reconhecimento da importância dos saberes tradicionais e da busca por novas técnicas e conceitos. As comunidades estudadas, na medida em que exibem a valorização do conhecimento tradicional, expressam sua força endógena de resistência às pressões urbanas e turísticas que ocorrem no local (TOLEDO; BARRERA-BASSOLS, 2009).

Segundo Guzmán (2001), cada comunidade apresenta respostas internas às agressões socioculturais sofridas pela modernização. $\mathrm{O}$ autor pontua que é preciso articular o conhecimento tradicional com as inovações científicas. Desta maneira as externalidades são incorporadas e adaptadas à cultura endógena com respeito à identidade local, gerando qualidade de vida e melhorias no manejo ecológico dos recursos naturais (GUZMÁN, 2001). Portanto, faz-se necessário que as ações de ATER potencializem as forças sociais internas, nesse caso, o valor dado tanto ao conhecimento tradicional quanto à necessidade de novas informações (TOLEDOBARRERA BASSOLS, 2009). Os agricultores devem ser incluídos desde o planejamento das ações, pois ao conhecer as demandas locais constroem-se ações conjuntas mais efetivas e condizentes com a realidade (ALTIERI; TOLEDO, 2011). É preciso evitar que as informações sejam impostas aos agricultores de maneira arbitrária, para impedir o fracasso das ações (KERBER; ABREU, 2010).

Assim sendo, observou-se baixa percepção dos SE provenientes da Floresta Atlântica entre os agricultores entrevistados. As pressões urbano- turísticas e as limitações de uso do PESM vêm diminuindo a dependência direta dos SE por parte das comunidades rurais estudadas. É possível que a perda dos conhecimentos tradicionais e da relação íntima com a natureza esteja acontecendo. Portanto, é necessário valorizar o interesse desses atores nos conhecimentos tradicionais e nos novos aprendizados. Tal valorização pode ser intermediada por agentes de ATER apoiados por técnicos do PESM, de modo que se construam planejamentos e ações com a participação dos atores locais. A partir disso, as estratégias de conservação e as práticas agrícolas podem vir a ser condizentes com a realidade local e se tornarem mais eficazes na proteção tanto da Floresta Atlântica e dos seus recursos como da cultura e do modo de vida dessas comunidades.

\section{Referências}

ABRAM, N. K.; MEIJAARD, E.; ANCRENAZ, M.; RUNTING, R. K.; WELLS, J. A.; GAVEAU, D.; PELLIER A. S.; MENGERSEN, K. Spatially explicit perceptions of ecosystem services and land cover change in forested regions of Borneo. Ecosystem Services, Amsterdam, v. 7, p. 116-127, 2014.

ADAMS, C. Identidade caiçara: exclusão histórica e sócioambiental. In: SIMPÓSIO BRASILEIRO DE ETNOBIOLOGIA E ETNOECOLOGIA, IV, 2002, Recife. Anais... Recife: Sociedade Brasileira de Etnobiologia e Etnoecologia, 2002. p. 27-43.

ALTIERI, M. A.; TOLEDO, V. M. The agroecological revolution in Latin America: rescuing nature, ensure food sovereingnty and empowering peasants. Journal of Peasant Studies, London, v. 38, n. 3, p. 587-612, 2011.

AMOROZO, M. C. M.; MING, L. C.; SILVA, S. M. P. (Ed.) Métodos de coleta e análises de dados em etnobiologia, etnoecologia e disciplinas correlatas. Rio Claro: UNESP/CNPQ, 2002. 204 p.

ASSIS, R. L. Desenvolvimento rural sustentável no Brasil: perspectivas a partir da integração de ações públicas e privadas com base na Agroecologia. Economia Aplicada, Ribeirão Preto, v. 10, n. 1, p. 75-89, 2006.

BARBOSA, S. R. C. S.; FORMAGIO, C. C.; BARBOSA, R. V. Áreas protegidas uso e ocupação do solo, qualidade de vida e turismo no litoral norte paulista: algumas reflexões sobre o município de Ubatuba. Caderno Virtual de Turismo, Rio de Janeiro, v. 10, n. 2, p. 121-137, 2010.

BARRENA, J.; NAHUELHUAL, L.; BÁEZ, A.; SCHIAPPACASSE, I.; CERDA, C. Valuing cultural ecosystem services: agricultural heritage in Chiloé island, southem Chile. Ecosystem Services, Amsterdam, v. 7, p. 66-75, 2014.

BARRERA-BASSOLS, N.; TOLEDO, V. Ethnoecology of the Yucatec Maya: symbolism, knowledge and management of natural resources. Journal of Latin American Geography, Austin, v. 4, n. 1, p. 9-41, 2005. 
BORGES, R.; PEIXOTO, A. L. Conhecimento e uso de plantas em uma comunidade caiçara do litoral sul do Estado do Rio de Janeiro, Brasil. Acta Botanica Brasilica, Belo Horizonte, v. 23, n. 3, p. 769 779, 2009.

BRITO, M. R.; SENNA-VALLE, L. Diversity of plant knowledge in a "Caiçara" community from the Brazilian Atlantic Forest coast. Acta Botanica Brasilica, Belo Horizonte, v. 26, n. 4, p. 735-747, 2012.

BUQUERA, R. B. A agroecologia e os serviços ecossistêmicos: um estudo de caso nos assentamentos de Iperó/SP. 2015. $117 \mathrm{f}$. Dissertação (Mestrado em Agroecologia e Desenvolvimento Rural) - Universidade Federal de São Carlos, Araras. 2015.

CAMARGO, P. Fundamentos da transição agroecológica: racionalidade ecológica e campesinato. Agrária, Recife, n. 7, p. 156181, 2007.

CAMPOS, M.; VELÁZQUEZ, A.; VERDINELLI, G. B.; PRIEGOSANTANDER, A. G.; MACCALL, M. K.; BOADA, M. Rural people's knowledge and perception of lanscape: a case study from the Mexican pacific coast. Society and Natural Resources, Huntsville, v. 25, n. 8 , p. $759-774,2011$.

CAMPOS, M. M. S. Ecofisiologia do uso de nitrogênio em espécies arbóreas da floresta ombrófila densa das terras baixas, Ubatuba, SP. 2009. 102 f. Dissertação (Mestrado em Biodiversidade Vegetal e Meio Ambiente) - Instituto de Botânica da Secretaria do Meio Ambiente, São Paulo. 2009.

CAPORAL, F. R. Agroecologia: uma nova ciência para apoiar a transição para agriculturas mais sustentáveis. Brasília: MDA/SAF, 2009. $30 \mathrm{p}$.

CARNEIRO, M. J. Ruralidade: novas identidades em construção. Estudos Sociedade e Agricultura, Rio de Janeiro, n. 11, p. 53-75, 1998.

CATI - COORDENADORIA DE ASSISTÊNCIA T CNICA INTEGRAL. Levantamento censitário das unidades de produção agropecuária do estado de São Paulo (LUPA 2007/2008). 2015. Disponível em: <http://www.cati.sp.gov.br/projetolupa/>. Acesso em: 21 ago. 2015.

CHAN, K. M. A.; GUERRY, A. D.; BALVANERA, P.; KLAIN, S.; SATTERFIELD, T.; BASURTO, X.; BOSTROM, A.; CHUENPAGDEE, R.; GOULD, R.; HALPERN, B. S.; HANNAHS, N.; LEVINE, J.; NORTON, B.; RUCKELSHAUS, M.; RUSSELL, R.; TAM, J.; WOODSIDE, U. Where are cultural and social in ecosystem services? A framework for constructive engagement. BioScience, Uberlândia, v. 62, n. 8, p. 744-756, 2012.

COLlADO, A. C.; GALLAR, D.; CANDÓN, J. Agroecológía política: la transición social hacia sistemas agroalimentarios sustentables. Revista de Economia Crítica, La Rioja, n. 16, p. 244277,2013

COSTABEBER, J. A.; MOYANO, E. Transição agroecológica e ação social coletiva. Agroecologia e Desenvolvimento Rural Sustentável, Porto Alegre, v. 1, n. 4, p. 50-60, 2000.

DALMORA, E. O papel da agricultura familiar no processo de conservação da Mata Atlântica em Santa Catarina. Modos de apropriação e transformações no sistema de gestão ambiental na década de 90. 2004. 346 f. Tese (Doutorado em Ciências Humanas) Universidade Federal de Santa Catarina, Florianópolis. 2004.

DE GROOT, R. S.; WILSON, M. A.; BOUMANS, R. M. J. A typology for the classitication, description and valuation of ecosystem functions, goods and services. Ecological Economics, Amsterdam, v. 41, p. 393-408, 2002

DIEGUES, A. C. A construção da etno-conservação no Brasil: o desafio de novos conhecimentos e novas práticas para a conservação. São Paulo: NUPAUB, s/d. 7 p. Disponível em: $<$ http://nupaub.fflch. usp.br/sites/nupaub.fflch.usp.br/files/color/manausetnocon.pdf>. Acesso em: 13 abr. 2017.

DIEGUES, A. C. S. O mito moderno da natureza intocada. São Paulo: Hucitec Núcleo de apoio à pesquisa sobre populações humanas e áreas húmidas brasileiras, 2001. 169 p.

FAGERHOLM, N.; KAYHKO, N.; NDUMBARO, F.; KHAMIS, M. Community stakeholders' knowledge in landscape assessments - Mapping indicators for landscape services. Ecological Indicators, Amsterdam, v. 18, p. 421-433, 2012.

FLEURY, L. C.; ALMEIDA, J. Populações tradicionais e conservação ambiental: uma contribuição da teoria social. Revista Brasileira de Agroecologia, Porto Alegre, v. 2, n. 3, p. 3-19, 2007.

GLIESSMAN, S. R. Agroecología: processos ecológicos em agricultura sostenible. Turrialba: CATIE, 2002. 359 p.

GLIESSMAN, S. R.; ROSADO-MAY, F. J.; GUANDARRAMAZUGASTI, C.; JEDLICKA, J.; COHN, A.; MENDEZ, V. E.; COHEN, R.; TRUJILLO, L.; BACON, C.; JAFFE, R. Agroecología: promoviendo una transición hacia la sostenibilidad. Ecosistemas, Almería, v. 16, n. 1, p. 13-23, 2007.

GOMES, I.; TUBALDINI, M. A. S. A percepção ambiental na agricultura familiar. In: SIMPÓSIO NACIONAL SOBRE GEOGRAFIA, PERCEPÇÃO E COGNIÇÃO DO MEIO AMBIENTE, 2005, Londrina. Anais... Londrina: UEL, 2005. p. $1-11$.

GOTElli, J. E.; ELLiSON, A. M. Princípios de estatística em ecologia. Porto Alegre: Artmed, 2011. 528 p.

GUEDES, M. L. S.; BATISTA, M. A.; RAMALHO, M.; FREITAS, H. M. B.; SILVA, E. M. Breve incursão sobre a biodiversidade da Mata Atlântica. In: FRANKE, C. R.; ROCHA, P. L. B.; KLEIN, W.; GOMES, S. L (Ed.). Mata Atlântica e biodiversidade. Salvador: Edufba, 2005. p. 39-92.

GUZMÁN, E. S. Uma estratégia de sustentabilidade a partir da Agroecologia. Agroecologia e Desenvolvimento Rural Sustentável, Porto Alegre, v. 2, n. 1, p. 35-45, 2001.

HAMMER, O.; HARPER, D.A.; RYAN, P. D. Past: paleontological statistics software package for education and data analysis. Palaeontologia Electronica, Oslo, v. 4, n. 1, p. 1-9, 2001.

HANAZAKI, N.; TAMASHIRO, J. Y.; LEITÃO-FILHO, H. F.; BEGOSSI, A. Diversity of plant uses in two Caiçara communities from the Atlantic Forest coast, Brazil. Biodiversity and Conservation, New York, v. 9, p. 597-615, 2000.

HEIN, L.; KOPPEN, K.; DE GROOT, R. S.; IERLAND, E. C. Spatial scales, stakeholders and the valuation of ecosystem services. Ecological Economics, Amsterdam, v. 57, p. 209-228, 2006.

KERBER, M.; ABREU, L. S. Trajetórias de transição dos produtores de base ecológica de Ibiúna/SP e indicadores sociais de sustentabilidade. Sociedade e Desenvolvimento Rural, Brasília, v. 4, n. 1, p. 1-37, 2010.

LAMARQUE, P.; TAPPEINER, U.; TURNER, C.; STEINBACHER, N.; BARDGETT, R. D.; SZUKICS, U.; SCHERMER, M.; LAVOREL, S. Stakeholder perceptions of grassland ecosystem services in relation to knowledge on soil fertility and biodiversity. Regional Environmental Change, Berlin, v. 11, p. 791-804, 2011. 
LOVATTO, P. B.; ETGES, V. E.; KARNOPP, E. A natureza na percepção dos agricultores familiares do município de Santa Cruz do Sul, RS, Brasil: algumas perspectivas para o desenvolvimento regional sustentável. Redes, Santa Cruz do Sul, v. 13, n. 1, p. $225-$ 249, 2008.

MAFRA, M. S. H.; STADLER, H. H. C. Etnoconhecimento e conservação da biodiversidade em áreas naturais e agrícolas no planalto sul catarinense. In: CONGRESSO BRASILEIRO DE SISTEMAS, 2007, Campinas. Anais... Campinas: UNICAMP, 2009. p. 1-13.

MARTINEZ, E.; LIMA, A. C.; CASALINHO, H.; BIANCHI, M.; SILVA, D.; WINCKEL, T. Agricultura e ambiente: a percepção de agricultores de base familiar em diferentes agroecossistemas no território zona sul do Rio Grande do Sul. Cadernos de Agroecologia, Porto Alegre, v. 8, n. 2, p. 1-5, 2013.

MASERA, O.;ASTIER, M.; LÓPEZ-RIADURA, S. Sustentabilidad y manejo de recursos naturales: el marco de evaluación MESMIS. México: Mundi-Prensa, 1999. 109 p.

MAZOYER, M.; ROUDART, L. História das agriculturas no mundo: do neolítico à crise contemporânea. São Paulo: Editora UNESP; Brasília: NEAD, 2010. 568 p.

MEA - MILLENIUM ECOSYSTEM ASSESSMENT. Ecosystems and human well-being: synthesis. Washington: Island Press, 2005. $167 \mathrm{p}$.

MUHAMAD, D.; OKUBO, S.; HARASHINA, K.; PARIKESIT; GUNAWAN, B.; TAKEUCHI, K. Living close to forests enhances people's perception of ecosystem services in a forest-agricultural landscape of West Java, Indonesia. Ecosystem Services, Amsterdam, v. 8, p. 197-206, 2014.

MÜLLER, F.; BURKHARD, B. The indicator side of ecosystem services. Ecosystem Services, Amsterdam, v. 1, n. 1, p. 26-30, 2012. MYERS, M.; MITTERMEIER, R. A.; MITTERMEIER, C. G.; FONSECA, G. A. B.; KENT, J. Biodiversity hotspots for conservation priorities. Nature, New York, v. 403, p. 853-858, 2000.

OTANI, M. N.; SOUZA, M. C. M.; MOREIRA, S. R.; CASTRO, C. E.; MARCHIORI, A.; OLIVEIRA, M. D. M.; TURCO, P. H. N. Caracterização sociocultural dos agricultores familiares de Ubatuba, estado de São Paulo. Informações Econômicas, São Paulo, v. 41, n. 4, p. 17-28, 2011.

PACÍFICO, D. A.; SOGLIO, F. K. D. Transição para agricultura de base ecológica: um processo social. Revista Brasileira de Agroecologia, Porto Alegre, v. 5, n. 2, p. 50-64, 2010.

PANIZZA, A. C. Imagens orbitais, cartas e coremas: uma proposta metodológica para o estudo da organização e da dinâmica espacial. Aplicação ao município de Ubatuba, litoral norte, estado de São Paulo, Brasil. 2004. 299 f. Tese (Doutorado em Geografia Física) Universidade de São Paulo, São Paulo. 2004.

PILLA, M. A. C; AMOROZO, M. C. M. O conhecimento sobre os recursos vegetais alimentares em bairros rurais no Vale do Paraíba, SP, Brasil. Acta Botanica Brasilica, Belo Horizonte, v. 23, n. 4, p. 1190-1201, 2009.

RIBEIRO, M. C.; METZGER, J. P.; MARTENSEN, A. C.; PONZONI, F. J.; HIROTA, M. M. The Brazilian Atlantic Forest: how much is left, and how is the remaining forest distributed? Implications for conservation. Biological Conservation, Amsterdam, v. 142, p. 1141-1153, 2009.

RODRIGUES, M. L.; MALHEIROS, T. F.; FERNANDES, V.; DARÓS, T. D. A percepção ambiental como instrumento de apoio na gestão e na formulação de políticas públicas ambientais. Saúde e Sociedade, São Paulo, v. 21, n. 3, p. 96-110, 2012.

ROSA, M.; OREY, D. C. O campo de pesquisa em etnomodelagem: as abordagens êmica, ética e dialética. Educação e Pesquisa, São Paulo, v. 38, n. 4, p. 865-879, 2012.

RUA, J. A ressignificação do rural e as relações cidade-campo: uma contribuição geográfica. Revista da ANPEGE, Uberlândia, n. 2, p. 45-65, 2005.

SABOURIN, E.; THOMAS, S.; EGRET, L.; AVILA, M. L. Inovação social na comercialização de produtos orgânicos e agroecológicos da agricultura familiar no Distrito Federal. Sustentabilidade em Debate, Brasília, v. 5, n. 3, p. 98-119, 2014.

SANDHU, H. S.; WRATTEN, S. D.; CULLEN, R. From poachers to gamekeepers: perceptions of farmers towards ecosystem services on arable farmland. International Journal of Agricultural Sustainability, Abingdon, v. 5, p. 1-12, 2007.

SANTOS, C. F.; SIQUEIRA, E. S.; ARAÚJO, I. T.; MAIA, Z. M. G. A agroecologia como perspectiva de sustentabilidade na agricultura familiar. Ambiente e Sociedade, São Paulo, v. 17, n. 2, p. 33-52, 2014.

SILVA, S. R. Negros na Mata Atlântica, territórios quilombolas e a conservação da natureza. 2008. 370 f. Tese (Doutorado em Geografia) - Universidade de São Paulo, São Paulo. 2008.

SILVANO, R. A. M.; SILVA, A. L.; CERONI, M.; BEGOSSI, A. Contributions of ethnobiology to the conservation of tropical rivers and streams. Aquatic Conservation: Marine and Freshwater Ecosystems, Hoboken, v. 18, p. 241-260, 2008.

SILVANO, R. A. M.; UDVARDY, S.; CERONI, M.; FARLEY, J. An ecological integrity assessment of a Brazilian Atlantic Forest watershed based on surveys of stream health and local farmers' perceptions: implications for management. Ecological Economics, Amsterdam, v. 53, p. 369-385, 2005.

SIMÕES, E.; FERREIRA, L. C.; JOLY, C. A. O dilema de populações humanas em parques: gestão integrada entre técnicos e residentes no Núcleo Picinguaba. Sustentabilidade em Debate, Brasília, v. 2, n. 1, p. 17-32, 2011.

SWINTON, S. M.; LUPI, F.; ROBERTSON, G. P.; HAMILTON, S. K. Ecosystem services and agriculture: cultivating agricultural ecosystem for diverse benefits. Ecological Economics, Amsterdam, v. 64, n. 2, p. 245-252, 2007.

TOLEDO, V. M.; BARRERA-BASSOLS, N. A etnoecologia: uma ciência pós-normal que estuda as sabedorias tradicionais. Desenvolvimento e Meio Ambiente, Curitiba, n. 20, p. 31-45, 2009.

VERDEJO, M. E. Diagnóstico rural participativo: guia prático DRP. Brasília: MDA/Secretaria da Agricultura Familiar, 2006. 62 p.

VIANNA, L. P. De invisíveis a protagonistas: populações tradicionais e unidades de conservação. São Paulo: Annablume/ Fapesp, 2008. 340 p.

VODOUCHÊ, F. G.; COULIBALY, O.; ADÉGBIDI, A; SINSIN, B. Community perception of biodiversity conservation within protected areas in Benin. Forest Policy and Economics, Göttingen, v. 12, p. 505-512, 2010.

WANDERLEY, M. N. B. Agricultura familiar e campesinato: rupturas e continuidade. Estudos Sociedade e Agricultura, Rio de Janeiro, v. 21, p. 42-61, 2003. 